\title{
DESEMPENHO VITIVINÍCOLA DA CABERNET SAUVIGNON SOBRE DIFERENTES PORTA-ENXERTOS EM REGIÃO DE ALTITUDE DE SANTA CATARINA ${ }^{1}$
}

\author{
ALBERTO FONTANELLA BRIGHENTI ${ }^{2}$, LEO RUFATO ${ }^{3}$, \\ AIKE ANNELIESE KRETZSCHMAR ${ }^{4}$, CAROLINE SCHLEMPER ${ }^{5}$
}

RESUMO - Apesar de os porta-enxertos serem usados primariamente como uma forma de resistência a pragas, eles são uma ligação entre o solo e a copa, e desempenham um papel importante na adaptação da videira a fatores ambientais. O objetivo deste trabalho foi avaliar três porta-enxertos e dois sistemas de condução na produtividade do vinhedo, no crescimento da copa e nas características físicas dos frutos. O experimento foi conduzido em um vinhedo experimental da Epagri - Estação Experimental de São Joaquim, localizada no município de Painel (28॰01'02"S e 5008'57'O, altitude $1.200 \mathrm{~m}$ ). O trabalho foi executado com a cultivar Cabernet Sauvignon, enxertada sobre Paulsen 1.103 (Vitis berlandieri x Vitis rupestris), Couderc 3309 (Vitis riparia $\mathrm{x}$ Vitis rupestris) e 101-14 Mgt (Vitis riparia $\mathrm{x}$ Vitis rupestris), em dois sistemas de condução, espaldeira e manjedoura, com cinco anos de idade, no espaçamento de 3,0 x 1,5 m. O experimento foi avaliado nas safras de 2007/08 e 2008/09. Os tratamentos porta-enxerto e sistema de condução foram arranjados em um fatorial $(3 \times 2)$. O delineamento utilizado foi o de blocos ao acaso, com quatro blocos e 20 plantas por parcela. Foram avaliados a área foliar, a produtividade médias das plantas, o índice de Ravaz, o peso de material podado, o peso de cachos, peso de 50 bagas, o número de bagas por cacho, o diâmetro das bagas, os teores de sólidos solúveis, a acidez total, o $\mathrm{pH}$, os teores de antocianinas, o índice de polifenóis totais e os taninos. Plantas enxertadas em Paulsen 1.103 apresentaram as menores produtividades e as maiores áreas foliares. 3.309C é o porta-enxerto menos vigoroso e interfere de maneira positiva na frutificação efetiva, pois produz maior número de bagas por cacho e bagas mais pesadas. Os porta-enxertos 1.103P e 101-14 Mgt, apresentam os melhores resultados para antocianinas.

Termos para Indexação: Vitis vinifera L.; V. riparia $x$ V. rupestris; $V$. berlandieri $\mathrm{x} V$. rupestris.

\section{VITICULTURAL PERFORMANCE OF CABERNET SAUVIGNON GRAFTED ON DIFFERENT ROOTSTOCKS IN HIGH ALTITUDE REGIONS OF THE STATE OF SANTA CATARINA}

\begin{abstract}
Rootstocks are a link between the soil and the canopy; they play an important role in vine adaptation to environmental factors. The objective of this study was to evaluate three rootstocks and two training systems on vineyard productivity, scion growth and fruit physical features. The study was conducted in a experimental vineyard located at the city of Painel $\left(28^{\circ} 01^{\prime} 02^{\prime \prime} \mathrm{S}\right.$ and $50^{\circ} 08^{\prime} 57^{\prime \prime} \mathrm{W}$, altitude $\left.1200 \mathrm{~m}\right)$, in the state of Santa Catarina, Brazil. The cultivar evaluated was the Cabernet Sauvingon grafted on Paulsen 1103 (V. berlandieri $\mathrm{x}$ V. rupestris), Couderc 3309 and 101-14 Mgt (V.riparia $x$ V. rupestris), the training systems evaluated were vertical shoot positioning trellis and $\mathrm{Y}$ trellis. The plants were five years old and the spacing was 3,0 x 1,5 m. The experiment was evaluated at the seasons 2007/08 and 2008/09. The experimental design was randomized blocks, with four blocks and 20 plants per plot. The variables analysed were leaf area, productivity, Ravaz index, pruning weight, weight and diameter of the berries, cluster weight, number of berries per cluster, soluble solids contents, total acidity, $\mathrm{pH}$, anthocyanins contents, total polyphenols index and tannins. Plants grafted on 1103P presented the lowest productivity and biggest leaf area. The cultivar Couderc 3309 is the less vigorous rootstock, produces heavier berries and interferes positively on fruit set when increases the number of berries per cluster and berry weight. The rootstocks Paulsen 1103 and 101-14 Mgt, presents the best results for total anthocyanins contents.
\end{abstract}

Index terms: Vitis vinifera L.; V. riparia x V. rupestris; V. berlandieri $\mathrm{x}$ V. rupestris.

\footnotetext{
1(Trabalho 045-10). Recebido em: 04-02-2010. Aceito para publicação em: 03-09-2010.

${ }^{2}$ Engenheiro Agrônomo, mestrando Produção Vegetal CAV-UDESC; Av. Luiz de Camões 2090 Bairro Conta Dinheiro, Lages-SC, CEP: 88520-000. e-mail: brighenti_07@hotmail.com

${ }^{3}$ Orientador, Dr. Fruticultura, Professor CAV/UDESC, e-mail: leoruffato@yahoo.com.br

${ }^{4}$ Orientadora, Dra. Fruticultura, Professora CAV/UDESC, e-mail: a2aak@cav.udesc.br

${ }^{5}$ Engenheira Agrônoma, mestranda Produção Vegetal CAV-UDESC, e-mail: csgirl@bol.com.br
} 


\section{INTRODUÇÃO}

A partir do ano 2.000, houve expansão expressiva da vitivinicultura em regiões de elevada altitude do Estado de Santa Catarina. Nesses locais, a altitude elevada (1.200 a $1.400 \mathrm{~m})$, aliada à baixa latitude, proporciona deslocamento de todo o ciclo produtivo da videira, que se caracteriza por duas situações distintas em seus extremos. Por um lado, as baixas temperaturas noturnas retardam o início da brotação. Enquanto no outro extremo do ciclo vegetativo, na maturação, as temperaturas noturnas amenas retardam o amadurecimento dos frutos, reduzem o crescimento das plantas e influenciam no metabolismo. O resultado é que a colheita ocorre em um período onde, historicamente, os índices pluviométricos são menores que nos meses de colheita das regiões tradicionalmente produtoras, o que permite a maturação fenólica mais completa (BONIN; BRIGHENTI, 2006).

Porta-enxertos são usados em vinhedos desde a segunda metade do século XIX, como consequência da invasão da filoxera (Daktulosphaira vitifoliae) (PINKERTON et al., 2005). Hoje, eles são utilizados como adaptação a determinadas condições climáticas, diferentes tipos de solo, controle de pragas e doenças de solo (TERRA et al., 2003; MACHADO et al., 2005).

Dentro de certos limites, porta-enxertos que promovem aumento no grau de crescimento vegetativo podem ter efeito positivo na produtividade, ao afetar o tamanho da baga e a composição química da fruta (OLLAT et al., 2003).

O objetivo deste trabalho foi avaliar a influência de três porta-enxertos na produtividade e na qualidade da uva Cabernet Sauvignon, produzida nas regiões de altitude, do Estado de Santa Catarina.

\section{MATERIAL E MÉTODOS}

O experimento foi conduzido na empresa Hiragami's Fruit, no vinhedo experimental da Epagri - Estação Experimental de São Joaquim, localizada no município de Painel $\left(28^{\circ} 01^{\prime} 02^{\prime \prime} \mathrm{S}\right.$ e $50^{\circ} 08^{\prime} 57^{\prime \prime} \mathrm{O}$, altitude $1.200 \mathrm{~m}$ ), durante as safras de 2007/08 e 2008/09.

Os solos da região enquadram-se nas classes Cambissolo Húmico, Neossolo Litólicos e Nitossolo Háplico, desenvolvidos a partir de rocha riodacito e basalto. O clima é do tipo mesotérmico úmido com verões amenos, $\mathrm{Cfb}$ na classificação de Köeppen (EMBRAPA, 2004).

O trabalho foi executado com a variedade
Cabernet Sauvignon, enxertada sobre Paulsen 1.103 (Vitis berlandieri x Vitis rupestris), Couderc 3.309 (Vitis riparia $\mathrm{x}$ Vitis rupestris) e 101-14 Mgt (Vitis riparia $\mathrm{x}$ Vitis rupestris). As videiras conduzidas no sistema de espaldeira tinham cinco anos de plantio, no início da avaliação, e foram plantadas no espaçamento de $3,0 \times 1,5 \mathrm{~m}$. O delineamento utilizado foi o de blocos ao acaso, com quatro blocos e 20 plantas por parcela.

A colheita ocorreu em 09 de abril de 2008 e 23 de abril de 2009, seguindo os padrões da empresa, quando valores médios de $20^{\circ}$ Brix foram observados. Nesse momento, foi determinada a produtividade por planta $\left(\mathrm{kg}_{\text {planta }}{ }^{-1}\right) \mathrm{e}$, em seguida, foi calculada a produtividade estimada por hectare. No momento da colheita, foram amostrados quinze cachos por parcela de forma aleatória para a realização das análises físicas. Com o uso de balança analítica, determinaram-se o peso de cachos e o peso de cinquenta bagas. Com um paquímetro, obteve-se o diâmetro de bagas. Com uma régua graduada, determinou-o o comprimento dos cachos. Todas as análises foram realizadas nos laboratórios do Núcleo de Tecnologia de Alimentos (NUTA) do Centro de Ciências Agroveterinárias (CAV) da Universidade do Estado de Santa Catarina (UDESC).

A determinção da área foliar foi realizada com a amostragem de 50 folhas por parcela, e sua área média foi medida com um medidor de área foliar. Foram contados o número total de folhas por planta, e multiplicando-se pela área foliar média obteve-se a área foliar total média por planta. Entre abril e maio, quando os frutos atingiram a maturação comercial, as uvas das unidades experimentais foram colhidas e pesadas. Para se determinar o vigor das plantas, utilizaram-se o peso do material podado e o índice de Ravaz. O índice de Ravaz foi determinado como uma relação entre o peso dos frutos produzidos e o peso do material podado.

No momento da colheita, foram coletadas 100 bagas por parcela, localizadas na zona basal, mediana e apical de diferentes cachos, tanto do setor leste como do setor oeste das filas, segundo metodologia proposta por Rizzon e Mielle (2002). A partir do mosto das bagas, foi determinado o teor de sólidos solúveis (SST), utilizando um refratômetro óptico Instrutemp modelo RTA-50, e os resultados, expressos em ${ }^{\circ}$ Brix. Para determinar a acidez, utilizou-se a titulação do mosto com solução alcalina padronizada de $\mathrm{NaOH} 0,1 \mathrm{~N}$ e, como indicador, o azul de bromotimol, que vira a $\mathrm{pH} 7$, e os resultados, expressos em meq $\mathrm{L}^{-1}$. A determinação do potencial hidrogeniônico $(\mathrm{pH})$ do mosto foi realizada por meio de um potenciômetro marca Impac. 
Para determinar a concentração dos compostos fenólicos, utilizou-se uma subamostra de 50 bagas. Seguindo metodologia descrita por Iland et al. (2004), utilizou-se uma solução hidroalcoólica de etanol a $50 \% \mathrm{v} \mathrm{v}^{-1}$, ajustada a $\mathrm{pH} 2$, simulando a extração das antocianinas e polifenóis totais durante a fermentação alcoólica da vinificação. Essas condições, somadas à agitação constante, e o aquecimento em banho-maria por cinco minutos extraem aproximadamente $94 \%$ dos compostos fenólicos e é chamada de solução extrato.

A quantificação do aporte fenólico das bagas foi baseada na metodologia proposta por Glories (1998) e Ribéreau-Gayon et al. (1998), através da absorbância característica do ciclo benzênico, componente da maior parte dos polifenóis.

A concentração de antocianinas extraíveis foi estimada segundo a metodologia proposta por Ribéreau-Gayon e Stonestreet (1965) apud RibéreauGayon et al. (1998), método químico baseado na propriedade característica das antocianinas, as quais variam sua cor de acordo com o $\mathrm{pH}$. A quantificação do aporte de tanino às bagas foi baseada segundo metodologia baseada na despolimerização a quente, em meio ácido da cadeia de flavonoides (proantocianidina), transformando-a parcialmente em cianidina e delfinidina sob meio oxidante (RIBEREAU-GAYON et al., 1998).

Os dados obtidos foram submetidos a análise de variância (ANOVA) e ao teste de Tukey, a 5\% de probabilidade de erro, para determinar as diferenças entre os porta-enxertos.

\section{RESULTADOS E DISCUSSÃO}

A produtividade das plantas foi afetada pelos diferentes porta-enxertos (Tabela 1). Nos dois anos avaliados, o porta-enxerto mais vigoroso, Paulsen 1.103 , apresentou as menores produtividades, não diferindo do 3.309 C Mgt na safra de 2008 e não diferindo do 101-14 Mgt na safra de 2008/09. Os dados obtidos concordam com Wolf e Pool (1988) e Parejo et al. (1995). Esses autores relatam que a produtividade se correlaciona de forma negativa com o vigor da planta. Por outro lado, outros autores destacam que, dentro de certos limites, porta-enxertos que promovem um aumento no crescimento vegetativo terão um efeito positivo na produtividade (MAIN et al., 2002; McKENRY et al., 2004, FELDBERG et al., 2007).

Nos dois anos avaliados, observam-se grandes diferenças nas produtividades (Tabela 1), e a explicação para esse comportamento reside no fato de que, na safra de 2009, houve condições climáticas pouco favoráveis, como excesso de chuvas e frio no período da florada, no mês de novembro de 2008 .

Para o peso do material podado na safra de 2008/09 (Tabela 3), observa-se influência dos porta-enxertos. Paulsen 1.103 aparece como o mais vigoroso, enquanto Couderc 3.309 é o menos vigoroso e 101-14 Mgt possui um vigor intermediário. Essas informações confirmam o obtido por Shaffer et al. (2004), quando relataram as diferenças dos porta-enxertos quanto ao vigor conferido às plantas.

O índice de Ravaz é uma relação entre produção de frutos por planta $(\mathrm{kg})$ e o peso do material podado $(\mathrm{kg})$. Esse índice é utilizado para determinar o equilíbrio e o vigor das plantas. Segundo Yuste (2005), o índice de Ravaz exerce influência clara sobre a videira, que se encontra em equilíbrio quando os valores estão entre 4 e 7. Índices maiores que 7 indicam excesso de produção de frutos, e os menores que 4 demonstram vigor excessivo da planta. Os resultados observados na Tabela 3 encontram-se abaixo de 4, sugerindo que há vigor excessivo em todos os tratamentos,. Esse efeito poderia ser minimizado aumentando a carga de frutos. Possivelmente, esse índice tão baixo deve-se ao fato de que, na safra de 2008/09, houve queda na produtividade devido a problemas climáticos. Mesmo com esses baixos valores, observa-se que o porta-enxerto 3.309 C ainda proporcionou o maior equilíbrio para as plantas, graças ao seu reduzido vigor.

A área foliar das plantas também foi influenciada pelos porta-enxertos (Tabela 3). Observa-se que plantas enxertadas em $1.103 \mathrm{P}$ apresentaram as maiores áreas foliares. Resultados semelhantes foram encontrados por Sampaio (2007), que observou que, de maneira geral, porta-enxertos menos vigorosos estavam relacionados com menores áreas foliares, porém esse comportamento variava de acordo com o ano avaliado.

O peso de cachos, peso de 50 bagas e o número de bagas por cacho (Tabelas 1 e 2 ) foram afetados pelo porta-enxerto utilizado. Os maiores pesos de cacho foram observados em plantas enxertadas em 101-14 Mgt, que não diferiram dos pesos de cacho de plantas enxertadas sobre 3309 C. Os maiores pesos de 50 bagas e o maior número de bagas por cacho foram obtidos em plantas enxertadas em 101-14 Mgt. Resultados similares foram encontrados por Brighenti et al. (2010) e por May (1994), na Austrália, estudando a cv. Merlot. O aumento dos peso dos cachos, das bagas e do número de bagas por cacho pode ser associado a uma melhoria no percentual de frutificação efetiva. May (2004) observou que alguns porta-enxertos, como o Couderc 3.309, 101-14, 4453,420 A, 1.616 C e 5C, aumentam a frutificação, enquanto Paulsen 1.103, 161-49 e Gravesac não 
apresentaram efeitos.

Plantas conduzidas em espaldeira e enxertadas em 3.309 C , na safra de 2007/08, e enxertadas em 3.309 C e 1103 P na safra de 2008/09, produziram bagas de maior diâmetro (Tabela 2). Jackson e Lombard (1993) sugerem que os efeitos dos portaenxertos na composição da uva são, provavelmente, dependentes do vigor e, consequentemente, têm influência na expansão da copa e na exposição da fruta. A disponibilidade hídrica também é um fator importante para o aumento de tamanho da baga. Quanto maior for a quantidade de água disponível para a planta, maior será o tamanho da baga. Fregoni (1998) relata que há uma correlação inversa entre o teor de açúcar e o tamanho da baga. Para variedades destinadas a produção de vinhos tintos de qualidade, como é o caso da Cabernet Sauvignon, um aumento excessivo do tamanho da baga reduz a qualidade do mosto. Plantas conduzidas, enxertadas em 3.309 $\mathrm{C}$, possivelmente, absorveram mais água e, consequentemente, produziram bagas de maior tamanho.

Observa-se que os teores de sólidos solúveis dos frutos foram influenciados pelos porta-enxertos. Na safra de 2007/08, os menores valores de sólidos solúveis foram observados em uvas de plantas enxertadas em 3.309 C (Tabela 4). Alguns autores argumentam que porta-enxertos vigorosos prolongam o período vegetativo e, dessa forma, retardam o acúmulo de açúcar nas bagas (PRONGRÁCZ, 1983), enquanto outros relatam que o acúmulo de açúcar sofre atraso apenas em alguns porta-enxertos submetidos a excessiva produtividade, com elevada carga de frutos (SAMPAIO, 2007). Essa situação foi observada na Austrália, onde em situações de estresse, porta-enxertos pouco vigorosos induziram a um menor acúmulo de açúcar nas bagas quando comparados com uvas originadas de plantas mais equilibradas e de maior vigor (WITHING, 2004). Esse fato explica os resultados obtidos na safra de 2007/08, onde se observa que o porta-enxerto menos vigoroso foi responsável pelo menor acúmulo de açúcar nos frutos, devido às elevadas produtividades obtidas. Esse comportamento não se repetiu na safra seguinte, onde graças ao clima desfavorável houve uma redução na produtividade das plantas.

Na safra de 2008/09, observou-se que os frutos originados de plantas enxertadas em 1.103 $\mathrm{P}$ produziram frutos com menores teores de açúcar (Tabela 4). Esse comportamento pode ser explicado pelo vigor das plantas. Em ramos vigorosos, há uma atividade respiratória mais elevada que em ramos de médio a baixo vigor, nos quais há maior equilíbrio entre fotossíntese e respiração, e dessa forma há o depósito de maiores quantidades de açúcares nas bagas (FREGONI, 1998).

Os valores de acidez total (Tabela 4) variaram com as safras, observoando-se que, na safra de 2007/08, plantas enxertadas em 3.309 C produziram uvas com menor acidez, enquanto na safra de 2008/09, ocorreu o inverso. Os valores observados no trabalho também são inferiores aos obtidos por Rizzon e Miele (2002) quando estudaram a variedade Cabernet Sauvignon na Serra Gaúcha. Sabe-se que numerosos fatores ambientais são responsáveis pela acidez da uva, por exemplo, e altitudes elevadas ou locais que apresentam dias quentes e noites frias produzem frutos de maior acidez (FREGONI, 1998).

Os menores valores de $\mathrm{pH}$ (Tabela 4) obtidos foram originados de frutos de plantas enxertadas em 101-14 Mgt, não diferindo de frutos de plantas enxertadas em 1.103 P na safra de 2008/09. A acidez regula o $\mathrm{pH}$, que é muito importante no desempenho da fermentação malolática, para o sabor, estabilidade biológica e para a coloração do vinho. Fregoni (1998) observa que o pH ótimo para a elaboração de vinhos tintos não deve superar 3,2 .

Para a variável antocianinas (Tabela 5), observa-se que os valores obtidos de frutos de plantas sobre o porta-enxerto de vigor intermediário, 101-14 Mgt nas duas safras, não diferiram de plantas enxertadas em $1.103 \mathrm{P}$ e foram estatisticamente superiores aos obtidos no 3.309 C. Esses resultados estão relacionados ao equilíbrio entre a atividade vegetativa e a atividade reprodutiva da planta. Gil e Pszczólkowski (2007) argumentam que o vigor influencia de maneira notável na respiração. Um ramo vigoroso possui atividade respiratória muito elevada, de modo que o consumo de energia é maior que em ramos de médio a reduzido vigor, nos quais há maior equilíbrio entre fotossíntese e respiração. Plantas mais equilibradas acumulam nas bagas maiores quatidades de carboidratos, que são precursores das antocianinas. Enquanto ramos vigorosos produzem maiores quantidades de carboidratos, também os consomem em maior quantidade, para manter o crescimento vegetativo.

Para índice de polifenóis totais e os taninos (Tabela 5), observou-se comportamento similar, na safra de 2007/08. Em uvas originadas de plantas enxertadas em 101-14 Mgt, observaram-se valores para ambas as variáveis superiores aos demais portaenxertos. Os resultados observados para a variável índice de polifenóis totais estão relacionados com o vigor do porta-enxerto e o equilíbrio entre atividade vegetativa e reprodutiva, como foi relatado por Gil e Pszczólkowski (2007). Downey et al. (2004) observaram que o acúmulo de taninos na cv. Syrah não foi afetado pela exposição dos cachos e pelo vigor do porta-enxerto utilizado. Esses fatos estão 
relacionados com os resultados observados, visto que porta-enxertos tão distintos, como 1.103 P e 3.309 $\mathrm{C}$, não apresentaram diferenças siginificativas para os níveis de taninos na safra de 2007/08. Na safra de
2008/09, não foi observada diferença siginificativa entre porta-enxertos para índice de polifenóis totais e taninos. Possivelmente, esse resultado foi reflexo da queda na produtividade apresentada pelas plantas nessa safra.

TABELA 1 - Produtividade $\left(\mathrm{kg}_{\mathrm{p}} \operatorname{lanta}^{-1}\right.$ e ton há $\left.{ }^{-1}\right)$ e peso de cachos $(\mathrm{g})$ de uvas originadas de plantas da variedade Cabernet Sauvignon, enxertada sobre Paulsen 1.103, Couderc 3.309 e 101-14 Mgt, nas safras de 2007/08 e 2008/09. Lages, 2010.

\begin{tabular}{lccccccc}
\hline \multirow{2}{*}{ Porta-enxerto } & $\begin{array}{c}\text { Produtividade } \\
\left(\mathrm{kg} \mathrm{planta}^{-1}\right)\end{array}$ & \multicolumn{2}{c}{$\begin{array}{c}\text { Produtividade } \\
\left(\mathrm{t} \mathrm{ha}^{-1}\right)\end{array}$} & \multicolumn{2}{c}{$\begin{array}{c}\text { Peso Cacho } \\
(\mathrm{g})\end{array}$} \\
\cline { 2 - 8 } & $2007 / 08$ & $2008 / 09$ & $2007 / 08$ & $2008 / 09$ & $2007 / 08$ & $2008 / 09$ \\
\hline $1.103 \mathrm{P}$ & $4,73 \mathrm{~b}$ & $3,02 \mathrm{~b}$ & $10,51 \mathrm{~b}$ & $6,70 \mathrm{~b}$ & $165,98 \mathrm{~b}$ & $105,80 \mathrm{~b}$ \\
$3.309 \mathrm{C}$ & $5,11 \mathrm{ab}$ & $3,76 \mathrm{a}$ & $11,35 \mathrm{ab}$ & $8,35 \mathrm{a}$ & $173,09 \mathrm{ab}$ & $110,84 \mathrm{ab}$ \\
$101-14 \mathrm{Mgt}$ & $5,92 \mathrm{a}$ & $3,23 \mathrm{ab}$ & $13,14 \mathrm{a}$ & $7,17 \mathrm{ab}$ & $203,17 \mathrm{a}$ & $127,36 \mathrm{a}$ \\
\hline $\mathrm{CV}(\%)$ & 15,13 & 13,80 & 15,13 & 13,80 & 23,71 & 18,20 \\
\hline
\end{tabular}

* Médias seguidas por letras minúsculas distintas na coluna diferem entre si, pelo teste de Tukey, a 5\% de probabilidade de erro para o fator porta-enxerto.

TABELA 2 - Peso de 50 bagas (g), número de bagas por cacho e diâmetro de bagas ( $\mathrm{mm}$ ) de uvas originadas de plantas da variedade Cabernet Sauvignon, enxertadas sobre Paulsen 1.103, Couderc 3.309 e 101-14 Mgt, nas safras 2007/08 e 2008/09. Lages, 2010.

\begin{tabular}{lccccccc}
\hline \multirow{2}{*}{ Porta-enxerto } & \multicolumn{2}{c}{$\begin{array}{c}\text { Peso } 50 \text { Bagas } \\
(\mathrm{g})\end{array}$} & \multicolumn{2}{c}{$\mathrm{N}^{\circ}$ Bagas Cacho } & \multicolumn{2}{c}{$\begin{array}{c}\text { Diâmetro de Bagas } \\
(\mathrm{mm})\end{array}$} \\
\cline { 2 - 7 } & $2007 / 08$ & $2008 / 09$ & $2007 / 08$ & $2008 / 09$ & & $2007 / 08$ & $2008 / 09$ \\
\hline $1103 \mathrm{P}$ & $74,24 \mathrm{~b}$ & $69,61 \mathrm{~b}$ & $124,17 \mathrm{~b}$ & $123,08 \mathrm{c}$ & $11,74 \mathrm{ab}$ & $12,60 \mathrm{a}$ \\
$3309 \mathrm{C}$ & $74,01 \mathrm{~b}$ & $69,39 \mathrm{~b}$ & $121,33 \mathrm{~b}$ & $139,67 \mathrm{~b}$ & $12,43 \mathrm{a}$ & $12,34 \mathrm{a}$ \\
$101-14 \mathrm{Mgt}$ & $77,03 \mathrm{a}$ & $73,75 \mathrm{a}$ & $148,33 \mathrm{a}$ & $157,50 \mathrm{a}$ & $11,08 \mathrm{~b}$ & $11,83 \mathrm{~b}$ \\
\hline $\mathrm{CV}(\%)$ & 2,42 & 3,62 & 16,60 & 10,18 & 5,85 & 2,32 \\
\hline
\end{tabular}

* Médias seguidas por letras minúsculas distintas na coluna diferem entre si, pelo teste de Tukey, a 5\% de probabilidade de erro para o fator porta-enxerto.

TABELA 3 - Peso do material podado, índice de Ravaz e área foliar de uvas originadas de plantas da variedade Cabernet Sauvignon, enxertadas sobre Paulsen 1.103, Couderc 3.309 e 101-14 Mgt, na safra de 2008/09. Lages, 2010.

\begin{tabular}{lccc}
\hline Porta-enxerto & $\begin{array}{c}\text { Peso do Material Podado } \\
\left(\mathrm{kg} \mathrm{planta}^{-1}\right)\end{array}$ & $\begin{array}{c}\text { Índice de Ravaz } \\
\left(\mathrm{kg} \mathrm{uva} \mathrm{kg} \mathrm{material} \mathrm{podado}^{-1}\right)\end{array}$ & $\begin{array}{c}\text { Área Foliar } \\
\left(\mathrm{m}^{2}\right)\end{array}$ \\
\hline $1103 \mathrm{P}$ & $2,04 \mathrm{a}$ & $1,56 \mathrm{~b}$ & $7,28 \mathrm{a}$ \\
$3309 \mathrm{C}$ & $1,63 \mathrm{~b}$ & $2,05 \mathrm{a}$ & $4,84 \mathrm{~b}$ \\
$101-14 \mathrm{Mgt}$ & $1,76 \mathrm{ab}$ & $2,18 \mathrm{a}$ & $4,17 \mathrm{~b}$ \\
\hline $\mathrm{CV}(\%)$ & 17,51 & 20,77 & 21,63 \\
\hline
\end{tabular}

* Médias seguidas por letras minúsculas distintas na coluna diferem entre si, pelo teste de Tukey, a 5\% de probabilidade de erro para o fator porta-enxerto.

TABELA 4 - Teor de sólidos solúveis ( ${ }^{\circ}$ brix $)$, acidez total $\left(\right.$ meq L $\left.^{-1}\right)$ e pH de uvas originadas de plantas da variedade Cabernet Sauvignon, enxertadas sobre Paulsen 1.103, Couderc 3.309 e 101-14 Mgt, nas safras de 2007/08 e 2008/09. Lages, 2010.

\begin{tabular}{lcccccc}
\hline \multirow{2}{*}{ Porta-enxerto } & \multicolumn{2}{c}{$\begin{array}{c}\text { Sólidos Solúveis } \\
\left({ }^{\circ} \text { Brix }\right)\end{array}$} & \multicolumn{2}{c}{$\begin{array}{c}\text { Acidez } \\
\left(\text { meq } \mathrm{L}^{-1}\right)\end{array}$} & \multicolumn{2}{c}{$\mathrm{pH}$} \\
\cline { 2 - 8 } & $2007 / 08$ & $2008 / 09$ & $2007 / 08$ & $2008 / 09$ & $2007 / 08$ & $2008 / 09$ \\
\hline $1103 \mathrm{P}$ & $21,83 \mathrm{ab}$ & $20,23 \mathrm{~b}$ & $95,43 \mathrm{a}$ & $77,52 \mathrm{c}$ & $3,20 \mathrm{a}$ & $3,35 \mathrm{~b}$ \\
$3309 \mathrm{C}$ & $22,57 \mathrm{a}$ & $21,03 \mathrm{a}$ & $95,20 \mathrm{a}$ & $92,03 \mathrm{~b}$ & $2,79 \mathrm{~b}$ & $3,15 \mathrm{~b}$ \\
$101-14 \mathrm{Mgt}$ & $21,23 \mathrm{~b}$ & $21,40 \mathrm{a}$ & $79,79 \mathrm{~b}$ & $100,64 \mathrm{a}$ & $3,10 \mathrm{a}$ & $3,58 \mathrm{a}$ \\
\hline $\mathrm{CV}(\%)$ & 5,34 & 2,17 & 17,20 & 6,46 & 6,44 & 5,53 \\
\hline
\end{tabular}

* Médias seguidas por letras minúsculas distintas na coluna diferem entre si, pelo teste de Tukey, a 5\% de probabilidade de erro para o fator porta-enxerto. 
TABELA 5 - Teor antocianinas $\left(\mathrm{mg} \mathrm{L}^{-1}\right)$, índice de polifenóis totais (I280) e taninos $\left(\mathrm{mg} \mathrm{g}^{-1}\right)$ de uvas originadas de plantas da variedade Cabernet Sauvignon, enxertadas sobre Paulsen 1.103, Couderc 3.309 e 101-14 Mgt, nas safras de 2007/08 e 2008/09. Lages, 2010.

\begin{tabular}{|c|c|c|c|c|c|c|}
\hline \multirow[t]{2}{*}{ Porta-enxerto } & \multicolumn{2}{|c|}{$\begin{array}{l}\text { Antocianinas } \\
\left(\mathrm{mg} \mathrm{L}^{-1}\right)\end{array}$} & \multicolumn{2}{|c|}{$\begin{array}{l}\text { Polifenóis Totais } \\
\text { (I280) }\end{array}$} & \multicolumn{2}{|c|}{$\begin{array}{l}\text { Taninos } \\
\left(\mathrm{mg} \mathrm{g}^{-1}\right)\end{array}$} \\
\hline & $2007 / 08$ & $2008 / 09$ & $2007 / 08$ & $2008 / 09$ & $2007 / 08$ & $2008 / 09$ \\
\hline $1103 \mathrm{P}$ & $875,59 a b$ & $802,30 \mathrm{ab}$ & $34,68 \mathrm{c}$ & $64,42 \mathrm{a}$ & $1,34 \mathrm{~b}$ & $2,40 \mathrm{a}$ \\
\hline $3309 \mathrm{C}$ & $901,02 \mathrm{a}$ & $910,10 \mathrm{a}$ & $54,34 \mathrm{a}$ & $64,85 \mathrm{a}$ & $1,77 \mathrm{a}$ & $2,49 \mathrm{a}$ \\
\hline $101-14 \mathrm{Mgt}$ & $856,13 \mathrm{~b}$ & $753,80 \mathrm{~b}$ & $47,45 \mathrm{~b}$ & $66,84 \mathrm{a}$ & $1,41 \mathrm{~b}$ & $2,59 \mathrm{a}$ \\
\hline CV $(\%)$ & 4,31 & 5,47 & 7,34 & 7,84 & 19,74 & 10,45 \\
\hline
\end{tabular}

* Médias seguidas por letras minúsculas distintas na coluna diferem entre si, pelo teste de Tukey, a 5\% de probabilidade de erro para o fator porta-enxerto.

\section{CONCLUSÕES}

Nas regiões de altitude, os porta-enxertos de vigor baixo a intermediário, como Couderc 3.309 e 101-14 Mgt, conferem maior equilíbrio entre a parte vegetativa e reprodutiva das plantas, influenciando de maneira positiva na produtividade e na qualidade das uvas destinadas à produção de vinhos finos.

\section{REFERÊNCIAS}

BONIN, V.; BRIGHENTI, E. Aspectos climáticos e produção de vinhos finos na serra catarinense. In: ENCONTRO NACIONAL SOBRE FRUTICULTURA DE CLIMA TEMPERADO, 7., 2006. Fraiburgo. Anais... Fraiburgo: Epagri, 2006. 368 p.

BRIGHENTI, A. F.; RUFATO, L.; KRETZSCHMAR, A. A.; MADEIRA, F. C. Desponte dos ramos da videira e seu efeito na qualidade dos frutos de 'Merlot' sobre os porta-enxertos 'Paulsen 1.103' e 'Couderc 3.309'. Revista Brasileira de Fruticultura, Jaboticabal, v. 32, n.1 p. 019-026, 2010.

DOWNEY, M. O.; HARVEY, J. S.; ROBINSON, S. P. The effect of bunch shading on berry development and flavonoid accumulation in Shiraz grapes. Australian Journal of Grape and Wine Research, Adelaide, v.10, p. 55-73. 2004.

EMBRAPA. Empresa Brasileira de Pesquisa Agropecuária. Centro Nacional de Pesquisa de Solos. Solos do Estado de Santa Catarina. Rio de Janeiro: Embrapa Solos, 2004. 726p. (Boletim de Pesquisa e Desenvolvimento, 46).
FELDBERG, N. P.; REGINA, M. A.; DIAS, M. S. C. Desempenho agronômico das videiras 'Crimson Seedless' e 'Superior Seedless' no norte de Minas Gerais. Pesquisa Agropecuária Brasileira, Brasília, v.42, n.6, p. 777-783. 2007.

FREGONI, M. Viticoltura di qualitá. Verona: Edizione I'Informatore Agrário, 1998. 707p.

GIL, G.F.; PSZCZÓLKOWSKI, P. Viticultura: fundamentos para optimizar producción y calidad. Santiago: Ediciones Universidad Católica de Chile, 2007. 535p.

GLORIES, Y. La couleur des vins rouges. Les equilibres des anthocyanes et des tanins du Vin. Bordeaux: Actualités, 1998. 417p.

ILAND, P.; BRUER, N.; EDWARDS, G.; WEEKS, S.; WILKES, E. Chemical analyses of grapes and wine: techniques and concepts. Austrália: Campbelltown, 2004. 48p.

JACKSON, D. I.; LOMBARD, P. B. Environmental and management practices affecting grape composition and wine quality - A review. American Journal of Enology and Viticulture, Davis, v.44, p. 409-430, 1993.

MACHADO, M. P.; MAYER, J. L. S.; RITTER, M.; BIASI, L. A. Ácido indolbutírico no enraizamento de estacas semilenhosas do porta-enxerto de videira 'VR043-43' (Vitis vinifera x Vitis rotundifolia). Revista Brasileira de Fruticultura, Jaboticabal, v. 27, n.3, p. $476-479,2005$.

MAIN, G.; MORRIS, J.; STRIEGLER, K. Rootstock effects on Chardonel productivity, fruit, and wine composition. American Journal of Enology and Viticulture, Davis, v.53, p.37-40, 2002. 
MAY, P. Flowering and Fruitset in Grapevines. Adelaide: Lythum Press Pty, 2004. 120p.

MAY, P. Using grapevine rootstocks, the Australian perspective. Cowandilla: Winetitles, $1994.62 \mathrm{p}$

MCKENRY, M. V.; LUVISI, D.; ANWAR, S. A.; SCHRADER, P.; KAKU, S. Eight-year nematode study from uniformly designed rootstock trials in fifteen table grape Vineyards. American Journal of Enology and Viticulture, Davis, v.55, p. 218227. 2004.

OLLAT, N.; TANDONNET, J. P.; LAFONTAINE, M.; SCHULTZ, H. R. Short and long term effects of three rootstocks on Cabernet Sauvignon vine behaviour and wine quality. Acta Horticulturae, Wageningen, n. 617, p. 95-99, 2003.

PAREJO, J.; MINGUEZ, S.; SELLA, J.; ESPINAS, E. Sixteen years of monitoring the cultivar Xarello (Vitis vinifera L.) on several rootstocks. Acta Horticulturae, Wageningen. N.388, p.123-128. 1995.

PINKERTON, J. N.; VASCONCELOS, M. C.; SAMPAIO, T. L.; SHAFFER, R. G. Reaction of grape rootstocks to ring nematode Mesocriconema xenoplax. American Journal of Enology and Viticulture, Davis, v. 56, p. 377 - 385, 2005.

PONGRÁCZ, D. P. Rootstocks for grapevines. Cape Town: David Philip, 1983.

RIBEREAU-GAYON, P.; GLORIES, Y. ; MAUJEAN, A. ; DUBOURDIEU, D. Traité dóenologie. 2. Chimie du vin: stabilisiation et traitements. Paris: Dumond, 1998. v.2, 519p.
RIZZON, L. A.; MIELLE, A. Avaliação da cv. Cabernet Sauvignon para a elaboração de vinho tinto. Ciência e Tecnologia de Alimentos, Campinas, v.22, n.2, p.192-198, 2002.

SAMPAIO, T. L. B. Using rootstocks to manipulate vine physiological performance and mediate changes in fruit and wine composition. $2007.240 \mathrm{f}$. Tese (PHD) - Oregon State University, Oregon, 2007.

SHAFER, R.; SAMPAIO, T. L. B.; PINKERTON, J.; VASCONCELOS, M. C. Grapevine rootstocks for Oregon vineyards. Oregon: State University, 2004. $11 \mathrm{p}$.

TERRA, M. M.; PIRES, E. J. P.; POMMER, C. V.; BOTELHO, R. V. Produtividade da cultivar de uva de mesa niagara rosada sobre diferentes porta-enxertos, em Monte Alegre do Sul-SP. Revista Brasileira de Fruticultura, Jaboticabal, v. 25, n. 3, p. 549-551, 2003.

WHITING, J. R. Grapevine rootstocks. In: DRY, P.R.; COOMBE, B.G. (Ed.). Viticulture: resources in Austrália. Ashford: Winetitles, 2004. p. 167-188

WOLF, T. K.; POOL, R. M. Effects of rootstock and nitrogen fertilization on the growth and yield of Chardonnay grapevines in New York. American Journal of Enology and Viticulture, Davis, v.39, p. 29-37. 1988.

YUSTE, D.J. Factores de desequilibrio de la vid: alternativas para el manejo eficaz del potencial vegetativo hacia el equilibrio del viñedo. In: $\mathrm{CON}$ TROL DEL VIGOR Y DEL RENDIMIENTO EN EL MARCO DE UNA VITICULTURA DE CALIDAD, 1., 2005, La Rioja. Anais... LaRioja: APROVI, 2005. 